\title{
Understanding the Scope for a Product Design Education Discourse on Additive Manufacturing
}

Jennifer Loy*

University of Technology Sydney, Sydney, Australia

\begin{abstract}
Background Additive manufacturing has the potential to disrupt conventional manufacturing. The argument presented in this article is that because product design students need to be achieving an advanced level of design for additive manufacturing to effectively utilise the technology in the near future, product design academics need to be researching the development of more advanced, discipline specific, learning objectives for designing to their constraints and opportunities. These need to address designing for complex technical applications and critically engage with implications for the future of design for manufacturing. The rationale underpinning this argument is based on a systematic quantitative literature review of research addressing design for additive manufacturing education.
\end{abstract}

Methods The systematic quantitative literature review provides a survey view of a sample data-base (Scopus), focussing on peer reviewed journal articles and conference papers, and also analysis of two leading design research journals, Design Studies and Design Issues based on searches capturing data on additive manufacturing or $3 \mathrm{D}$ printing, product design and education. These were refined by date, authority (based on publication source) and relevance. The analysis provides an overview of the product design discipline's response to the topic and highlights issues.

Results An initial scoping search of the terms for title, abstract or keywords in Scopus identified 3720 published articles, from 2009-2017 rising each year: 59, 67, 84, 125, 192, 358, 666, 949,1220 . The data from a systematic quantitative literature review was analysed through the lens of sociotechnology theory, to foster a perspective on educational research at the intersection of technology and society. The results showed the majority of peer reviewed publications were written by engineering and architecture researchers, rather than product design academics (11\%). Analysis of design publications showed an emphasis on $3 \mathrm{D}$ printing as a prototyping tool supporting other learning activities, rather than a focus in itself. A small proportion of publications advanced design for additive manufacturing education, both technically and in a broader economic, environmental and social context.

Conclusions Overall, product design academics are not demonstrating the same level of engagement with research into additive manufacturing other discipline faculty members are, for example engineering and architectural. The implications are that a body of knowledge specific to product design is not being developed at the same pace and the potential disruption of design for manufacturing principles, practice and organization by additive manufacturing not yet addressed.

Keywords Innovation, 3D Printing, Digital, Technology, Disruption

* Corresponding author: Jennifer Loy (Jennifer.Loy@uts.edu.au)

Citation: Loy, J. (2018). Understanding the Scope for a Product Design Education Discourse on Additive Manufacturing. Archives of Design Research, 31(2), 15-23.

http://dx.doi.org/10.15187/adr.2018.05·31.2.15

Received : Jan. 19. 2018 ; Reviewed : Feb. 03. 2018 ; Accepted : Feb. 08. 2018

pISSN 1226-8046 eISSN 2288-2987

Copyright : This is an Open Access article distributed under the terms of the Creative Commons Attribution NonCommercial License (http://creativecommons.org/licenses/by-nc/3.o/), which permits unrestricted educational and non-commercial use, provided the original work is properly cited. 


\section{Introduction}

University education is based on the body of knowledge accumulated in a discipline over time. Whilst new programs may be developed, such as in technology and innovation, they are often adaptations of existing programs, or at the intersection of knowledge from multiple disciplines, such as business and engineering, providing academics with a solid base of foundational knowledge.

As discussed by Kozel (2013), key turning points that impact the direction and development of the product design discipline are related to "cultural and technical phenomena, but also social developments". For all disciplines, the evolution of digital technologies over the past twenty years has created challenges to established thinking and practice. Zysmann and Kenney (2017) outline the implications of emerging digital platforms for the future of work. In graphic design, for example, the internet is disrupting employment by supporting a 'gig' economy approach (project contracts-based employment), through changes to freelance practice on web sites such as 99 designs. For architecture, virtual reality has the potential to impact planning and construction of buildings (Du et al, 2018).

For product and industrial design, the digital revolution is still ongoing as the generation, analysis and application of data alters design outputs as well as the monitoring of products during use. However, a digital technology being heralded as having the potential to create a paradigm shift in manufacturing industries is additive manufacturing (Gibson et al 2014). Additive manufacturing refers to processes where parts are constructed layer by layer, using selective fusion, laser sintering or polymerization. It is commonly known as $3 \mathrm{D}$ printing (though this term is used predominantly to refer to desktop fused deposition modelling). Product-service systems thinking refers to the system that the product works within, and encompasses all aspects of the development, manufacturing, transportation, operation, maintenance and disposal of the product (Rajkumar \& Baxter, 2009). Because additive manufacturing does not require additional tooling, such as moulds, it challenges the current dominant production models and systems, as well as design for manufacturing principles.

For product and industrial design university-based education, the example of responding to emerging additive manufacturing techniques and potential for creating new ways of working in design and manufacturing, illustrates difficulties faced by universities in updating their curriculum in the face of significant change. The history of product and industrial design education as an applied discipline with requirements for professional practice, means that the university curriculum involves practical industry-informed knowledge in addition to the exploration of ideas beyond the workplace. This history of practice has been building since the inception of the discipline as a response to the industrial revolution that began in the nineteenth century (Forty, 1984). The origins of the profession are described by Forty through the examples of Chippendale and Wedgewood, and the necessity to separate out design and de-personalise the making process from the hand of individual makers in order to create uniformity to maximize the opportunities to scale-up provided by catalogue selling. The invention of the moving assembly line and mass production techniques, such as 
injection moulding consolidated this approach. Smaller ranges of product, ideally built from common components, larger inventory and generic designs replaced craft practice. Over the next hundred years, a myriad of manufacturing processes extended production capabilities. However, the underlying approach remained, based on the same principles. Professional design for mass production requires an in-depth knowledge of the technologies involved. For the designer in industry, working effectively with each new technology means understanding the constraints and opportunities they offer, based on mass production principles. All product and industrial design graduates are inducted into this way of working and key texts for the discipline, such as Product Design by Rodgers and Milton (2011), explain the practice principles and provide examples of processes and product outcome.

Additive manufacturing was invented as a rapid prototyping technique in the nineteeneighties, and was used by product designers from the mid-nineties for concept visualisation. The first additive manufacturing technique was stereo lithography, which is a resin-based process where the liquid is solidified as determined by a $3 \mathrm{D}$ computer model of the product that is sliced into layers in the computer ready for $3 \mathrm{D}$ printing. Although a useful tool for the product designer, this had narrow applications because of the limitations of the material. However, the principle of building layer by layer a $3 \mathrm{D}$ form without the need for tooling, such as moulds, or allowing for toolpaths, such as with computer numerically controlled milling, established a new way of forming.

Since the start of the twenty-first century, additive manufacturing has evolved from a prototyping technology to one suitable for end-use, production parts through a range of processes. This use of the technology for usable parts is a relatively new development, as material and technologies, such as fused deposition modelling, selective laser sintering and electron beam melting, have evolved. All are based on the principle of forming without the investment of pre-tooling. Whilst the technology overall is still in its infancy, it is creating an impact on established practices in major industries. For example, GE Additive has demonstrated its potential for aerospace design with production parts such as the Leap Fuel nozzle in 2012 creating a 30\% cost efficiency improvement, 25\% weight reduction and $95 \%$ inventory reduction. Their most recent component to be designed for additive manufacturing, the Advanced Turboprop Engine launched in 2017, consolidates 855 parts into 12, creates a $5 \%$ weight reduction and 20\% fuel burn reduction (source: Chris Schuppe Engineering Integration Leader GE, 2017. Image Kellner, 2017). Manufacturing across industry sectors will need to be in a position to respond to these competitive advantages in the near future, and product and industrial designers will need to be educated to a sufficient standard to be able to support that transition. This research aims to provide an evaluation of the current engagement of product and industrial design academics in research informing the development of advanced level learning activities that address design for additive manufacturing to a professional level, and critically examine the potential impact the technology could have on the evolution of the discipline. 


\section{3D printing publications}

A systematic quantitative literature review formed the basis of this article, supporting the narrative literature review embedded in the text, as well as a survey of speakers in selected international $3 \mathrm{D}$ printing conferences. The systematic, quantitative literature review was approached from two directions; a survey and a directed approach. In both cases the literature was limited to 2009 to 2017. This is because additive manufacturing for production parts became a realistic possibility during the first decade of the twenty-first century. The survey involved selecting a database that included key design texts (Scopus) and reviewing the literature based on searches designed to capture as thoroughly as possible relevant additive manufacturing and $3 \mathrm{D}$ printing publications. These included keyword and title searches using multiple combinations and selections from additive manufacturing, $3 \mathrm{D}$ printing, design, product and education. The results were refined by peer review to articles and conference papers, and then further by the publication source, excluding journals outside the scope, for example clinical research publications. The second approach was directed to provide a design-discipline specific review. For these searches, two top ranking design journals, Design Issues and Design Studies, were chosen for analysis. In each journal, two searches were based on keywords or titles including additive manufacturing and $3 \mathrm{D}$ printing. The results were then limited to articles (excluding book reviews etc.) from 2009 to 2017. Repeat results were removed in all searches as well as papers that on inspection were clearly out of place in the context of the search (for example, only mentioned the term in passing as part of a list). These articles were analysed for information on the discipline of the authors, the field of publication, the intent and focus of the articles and the inclusion of design for additive manufacturing that provided a foundation for advanced design for additive manufacturing, or engaged with advanced design for the technology through the lens of sociotechnology theory, that is with a focus on the intersection between society and technology.

\section{Curriculum development direction}

Based on the systematic quantitative literature review, engineering academic research predominantly focus on technical issues, such as layer adherence and material development. In broader university education examples, desk-top fused deposition modelers have been widely adopted across disciplines, particularly in science subjects (Ford and Minshall, 2017) for low-cost $3 \mathrm{D}$ prototypes. The dominant publication of research in this domain has been on the ability for these desk-top printers to support learning experiences with a different learning focus, for example, the study by Chen and Lin (2017) on gender and technology. The results of the journal article and conference paper reviews also suggested that the democratization of making was aninterest, and the potential impact on the future of the discipline. 
The incidence of publications by product design academics on the development of design for additive manufacturing skills in relation to the constraints and opportunities of the technology was low (11\%), with the majority of the publications from engineering and architectural academics. In comparison to architecture, this may in part be that the publications in architecture found in the review tended to be describing research into extending fused deposition modelling and robotic $3 \mathrm{D}$ printing into large scale projects, e.g. Leach (2017) and Lutkin (2014). For product design academics, the range of additive manufacturing techniques is extensive, and addresses the design of tooling, multi-material prototyping, and sand-casting moulds, as well as metal and polymer end-use parts (Gibson et al, 2014).

For product design academics, there is the added complications of the impact of product service systems thinking for the technology. As discussed by Diegel et al (2016), additive manufacturing has the potential to change the nature of manufacturing, for example, because of the lack of tooling required, it enables the iterative development of products in response to customer feedback. This increases the interaction between manufacturer and consumer and reduces the risk in launching new products. This type of innovation goes beyond the addition of a process to existing practice, it requires an innovation in the business model that organizes operations. Equally, additive manufacturing allows for print on demand, and distributed manufacturing, that Lipson and Kurman in Fabricated: The new world of 3D Printing (2013), describe as having the potential to also impact supply chains and the transport industry.

These possibilities have emerged at a time when, according to Gore (2013), a paradigm shift in product manufacturing, use and disposal is required for environmental reasons. According to Thakara (2011), "90\% of the resources taken out of the ground today become waste within three months", and in 2010. Americans generated 250 million tons of waste, of which 31 million tons of were plastics, which are the major element of marine debris (Decker, 2014). If it was possible to redesign production systems now, with knowledge of the environmental impact of manufacturing since the industrial revolution, high-value, invested, bespoke design utilizing additive manufacturing would more effectively meet sustainability imperatives and resource management targets, for example outlined by Ryan (2004), than current mass production strategies. The same level of scaling up, and centralization of manufacturing is unlikely to be achievable with additive manufacturing because of the nature of the processes involved, but as the economic destruction in Detroit has illustrated, concentrated manufacturing facilities can bring economic and social problems.

For the product design graduates of the future, the ability to design for additive manufacturing to a professional level will be an advantage, if not a requirement. If the adoption of additive manufacturing as a sustainability strategy can provide a more balanced model of consumerism in a circular economy, as suggested by Diegel (2016), then design students will need to go beyond the basics of the technology to engage with its potential as part of new ways of working for the industries of the future. To do this effectively, they will need learning experiences that extend their in-depth practical knowledge of the technology beyond the desktop printers, and, importantly to learn how to design for high-end technologies. 
Based on the evidence of the design projects reviewed in the systematic quantitative literature review, some product design academics are developing curriculum designed to advance students' knowledge of designing to the constraints and opportunities of the technologies for end-use parts, to an advanced level or using a systematic foundation approach, for example by Lindley et al (2014), where 3D printing learning in addressed in a similar way to that of other technologies, with documented experiments on optimizing design. There was evidence of academics researching the implications of the technology for traditional education (e.g. in engineering by Minetola et al 2015) and the development of making beyond the classroom, such as the fabrication lab on wheels suggested by Thurn et al (2017) and external workshops (e.g. Chao et al 2016). However, there was little evidence of learning activities that critically engaged the students' in the social and economic disruptions the technology could bring. The majority of the projects focused on the use of based fused deposition desk-top printers to support other activities, and where high-end equipment was used by students, still the emphasis was on rapid prototyping and emulating existing manufacturing processes.

Based on the results of the systematics quantitative literature review, even as the range of high-end processes suitable for production outputs have evolved, for product designers additive manufacturing has predominantly remained a prototyping tool to test the viability of a design prior to conventional manufacturing. Students have embraced low-cost, desktop printers for visual prototyping, particularly for scale models. This creates two problems, the first is when accurate representations of detailing for mass production processes, such as ribbing, draft angles, parting lines and ejector pins for injection moulding, are not detailed in a prototype, providing the student with unrealistic expectations about the viability of the design. Konstanin Grcic, in The Making of Design, (Tersiege, 2009), referred to the 'seduction' of a modelling technique that provides the designer with a false sense of what is possible in the end use material. Second, students mimicking other techniques rather than studying the scope and limitations of the technology itself are not learning how to use additive manufacturing properly.

\section{Conclusion}

Whilst there is evidence that product design academics are utilizing $3 \mathrm{D}$ printing in the curriculum, predominantly the body of knowledge informing an advanced level of design for additive manufacturing is currently housed and curated by engineering and architectural academic disciplines. The systematic literature review of the articles published over the last eight years by two design journals - Design Issues and Design Studies, selected as examples of leading publications that, based on their citations, inform and influence design disciplines, suggested that whilst there has been a rise in the number of articles published in both journals involving additive manufacturing, the percentage has been relatively small, and their focus less on advancing the body of knowledge and rethinking of product service systems than the democratization of making and its ability to support applications indirectly related to product and industrial design research. This is supported by a review of speakers for four international 3D printing conferences in 2017, Inside 3D Printing (Seoul, New York, 
Melbourne, San Diego), where only 10 out of 124 were product designers. The discipline has yet to develop an articulated body of research that projects into the future how it would be possible to move beyond the theories espoused on the democratization of making by Pettis (2011), Warner et al (2014) and others to realistically rethink production futures that respond to current imperatives and provide professional outcomes.

The statement "in the future, everyone will be a designer" can be traced back to Chris Bangle, the former director at BMW, who argued in 2005 that in a future with ubiquitous access to $3 \mathrm{D}$ Printing, design would become just as important as literacy and would have to be taught in schools...Bangle argues that when everyone was a designer, this would put pressure on the design profession itself." (Warner et al (2014, p.33))

Currently utopian ideas can confuse the differences between low-cost desktop printers and expensive, large, high maintenance industrial printers, for example for titanium powder direct laser melting. If the potential of the technology is to be realized, and if product designers are to be part of the evolution, rather than the discipline undermined by it, then the percentage of publications by product design academics on relevant research arguably needs to rise.

For over a hundred years, mass production has predominantly provided the guiding principles for graduates learning about the product and industrial design disciplines. With the disruptive potential of digital fabrication technology capable of producing customized product solutions, this could be changing. However, a review of relevant literature suggests that without more product design publications, the curation of knowledge in the field will remain with engineers and architects. This study does not analyse whether the results relate to the topic preferences of design journals, or the quality of research in this area by product design academics in comparison to established research teams in this field in engineering and architecture, or if academics are not choosing to engage with the topic to an advanced level.

This research provides the basis for recommendations for product and industrial design academics:

- Ensure that students learning with desktop printers involves learning to design for the technology, rather than solely producing prototypes for existing technologies.

- Create learning experiences that advance the students' knowledge and understanding of additive manufacturing and designing for the constraints and opportunities the different types of process allow.

- Critically engage more overtly as a product design community with the potential impact of the technology on the design profession and manufacturing, for example in terms of supporting sustainability targets, and in terms of changes in practice and the potential for innovation through a rethinking of business practices and models.

For product and industrial design academics, there are challenges that the change of manufacturing paradigm creates, not least the professional development it suggests and the need to surrender the role of expert that the accumulated body of knowledge current practice 
is based on affords. Product design academics need to research additive manufacturing fully informed on the production methods, future-focused and with a designer's mind.

\section{References}

1. Chen, A. C. Y., \& Lin, Y. C. (2017, July). Girls in Robot Class_Smart Textiles Interactive Tool-Kits to Enhance the Participatory of Women in Technology. In International Conference on Learning and Collaboration Technologies (pp. 134-147). Springer, Cham.

2. Decker, J. (2014). The Plastic Ocean. Anchorage: Booth-Clibborn.

3. Diegel, O., Kristav, P., Motte, D., \& Kianian, B. (2016). Additive Manufacturing and its Effect on Sustainable Design. In Muthu, S. S., \& Savalina, M. M. (Eds.), Handbook of Sustainability in Additive Manufacturing. New York: Springer.

4. Du, J., Zou, Z., Shi, Y., \& Zhao, D. (2018). Zero latency: Real time synchronization of BIM data in virtual reality for collaborative decision making. Automation in Construction, 85, 51-64.

5. Ford, S., \& Minshall, T. (2017). 3D printing in teaching and education: A review of where and how it is used. Additive Manufacturing. Retrieved January 15, 2018, from https://www.researchgate.net/pu blication/320617391_3D_printing_in_teaching_and_education_A_review_of_where_and_how_it_is_ used.

6. Forty, A. (1986). Objects of desire, design and society since 1750. London: Thames and Hudson.

7. Gibson, I., Rosen, D., \& Stucker, B. (2014). Additive manufacturing technologies: 3D printing rapid prototyping, and direct digital manufacturing (2nd ed.). Berlin: Springer.

8. Gore, A. (2013). The Future. New York: WH Allen.

9. Kellner, T. (2017). New One-of-a-Kind Turboprop Engine Delivers Jet-Like Simplicity To Pilots. Retrieved February 1, 2018, from https://www.ge.com/reports/new-one-kind-turboprop-enginedelivers-jet-like-simplicity-pilots/.

10. Kozel, N. (2013). Design: The ground breaking moments. London: Prestel Verlag.

11. Leach, N. (2017). What is 3D printed body architecture?. Architectural Digest, 87(6), 6-15.

12. Lindley, J., Adams, R., Beaufoy, J., \& McGonigal, S. (2014). A Traditional Approach to 3D Printing. In DS 78: Proceedings of the 16th International conference on Engineering and Product Design Education (E\&PDE14), Design Education and Human Technology Relations, University of Twente, The Netherlands, 04-05.09. 2014.

13. Lipson, H., \& Kurman, M. (2013). Fabricated: The new world of 3D Printing. Indianapolis: John Wiley \& Sons.

14. Minetola, P., Iuliano, L., Bassoli, E., \& Gatto, A. (2015). Impact of additive manufacturing on engineering education-evidence from Italy. Rapid Prototyping Journal, 21(5), 535-555.

15. Pettis, B. (2011). Made in My Backyard. Open Design Now. Netherlands: Bis.

16. Rajkumar, R., \& Baxter, D. (2009). Product-service systems. Journal of Engineering Design, 20(4), 327-328.

17. Rodgers, P., \& Milton, A. (2011). Product Design. London: Laurence King.

18. Rutkin, A. (2014). Watch as the world's first 3D-printed house appears. New Scientist, 221(2960), 24.

19. Terstiege, G. (2009). The making of design. Basel: Birkhauser Verlag.

20. Thackara, J. (2011). Open Design Now. Netherlands: Bis.

21. Thurn, L. K., Balc, N., Gebhardt, A., \& Kessler, J. (2017). Education packed in technology to promote innovations: Teaching Additive Manufacturing based on a rolling Lab. In MATEC Web of Conferences (Vol. 137, p. 02013). EDP Sciences.

22. Warnier, C., Werbruggen, D., Ehmann, S., \& Klanten, R. (Eds.). (2014). Printing Things: Visions and essentials for 3D Printing. Berlin: Gestalten.

23. Zysman, J., \& Kenney, M. (2017). Intelligent tools and digital platforms: Implications for work and employment. Intereconomics, 52(6), 329-334. 
